\title{
Aportes de la educación religiosa escolar a la promoción del pluralismo religioso ${ }^{1}$
}

\section{Contributions of school religious education to the promotion of religious pluralism}

\author{
Danilo Andrés Cantillo Cabrera ${ }^{2}$ \\ Fredy Alonso Quintero Torres ${ }^{3}$
}

DOI: 10.29151/hojasyhablas.n20a6

\section{Resumen}

La educación religiosa es vital para la formación integral del ser humano y su rol dentro del gran complejo de la educación es valioso para proponer al hombre de hoy una visión holística del mundo y de la realidad. El pluralismo religioso se inscribe en la nueva concepción del mundo moderno como una categoría constructora de respeto, aceptación del otro, tolerancia y fraternidad. La ERE en Colombia, a partir de la Constitución de 1991, ha recibido un marco legal que ha originado un cambio de perspectiva de la confesionalidad a la pluralidad de creencias. Es por ello que desde esta área del conocimiento se deben construir en las aulas de clases verdaderos areópagos de autoconocimiento y conocimiento del otro como afirmación de la propia identidad, que a su vez se abre a la experiencia de una educación religiosa orientada desde la pluralidad y la diversidad superando el viejo paradigma de la confesionalidad cerrada y absolutista.

Palabras clave: Educación religiosa; Pluralismo; Religión.

\begin{abstract}
Religious Education in vital for human beings' holistic formation. That is why its rol in education is critical to provide individuals with a wide perspective of the world and its reality. Religious Pluralism is part of a new vision of the world as it promotes respect, inclusion, tolerance and fraternity. The ERE in Colombia, grounded in the Constitution of 1991, developed a new legal framework that has allowed a change of the perspective: From confession to the acceptance of pluralism of believes. That is why, it is important to change classrooms into truly Areopagus of self-knowledge and knowledge of others as affirmation of self-identity. An identity opened to a new religious education, oriented by the pluralism principles and that transcends old paradigms of a narrow and absolutist confession.
\end{abstract}

Keywords: Religious education; Pluralism; Religion.

\footnotetext{
${ }^{1}$ Artículo de reflexión producto del trabajo investigativo de los autores realizado desde la Licenciatura en Filosofía y Educación Religiosa de la Universidad Santo Tomás - DUAD.

${ }^{2}$ Estudios realizados de Filosofía y Teología en el Seminario Regional de la Costa Atlántica Juan XXIII. Maestría en Teología Fundamental en la Pontificia Universidad Gregoriana de Roma. Licenciado en Filosofía y Educación Religiosa de la Universidad Santo Tomás. Docente del Colegio Eucarístico la Merced de Barranquilla. Correo de contacto: daniloandrescantillo@hotmail.com; danilocantillo@ustadistancia.edu.co; ORCID: https://orcid.org/0000-0001-5101-6393 ${ }^{3}$ Docente investigador en Educación Religiosa, Representaciones Sociales y Pedagogía. Magíster en Educación de la Universidad Santo Tomás. Licenciado en Filosofía y Educación Religiosa de la Universidad Santo Tomás. En la actualidad se desempeña como docente de tiempo completo de la Facultad de Educación de la Universidad Santo Tomás. Correo: fredyalqt@gmail.com; fredyquintero@ustadistancia.edu.co; ORCID: https://orcid.org/0000-0002-7922-4896
} 


\section{Introducción}

La globalización ha evidenciado que el mundo es plural y que los paradigmas de exclusión no tienen hoy por hoy asidero en la vida social y religiosa de los seres humanos. En el gran conjunto de la diversidad tiene un lugar muy importante el pluralismo religioso que es una exigencia que apremia de manera prioritaria a la Educación Religiosa Escolar (en adelante ERE) y la llama a dar una respuesta efectiva y afectiva desde su componente axiológico. En este contexto se propone el presente artículo, el cual consta de cuatro partes que aportarán elementos pertinentes sobre los aportes de la ERE al fenómeno del pluralismo religioso.

En la primera parte, se presenta un panorama histórico de la educación en Colombia que estuvo polarizada por la política estatal generando especialmente una ERE confesional desde el cristianismo católico y una educación liberal sin religión que generó pugnas entre conservadores y liberales. En la segunda parte, se realiza un estudio del marco legal de la ERE, partiendo de la Constitución de Colombia de 1991, de donde emanaron legislaciones educativas con vistas a una transición educativa que respeta la confesionalidad y abre caminos a la pluralidad de creencias desde el criterio de la trascendentalidad como un componente esencial de todo ser humano. En la tercera parte, se da una definición del pluralismo religioso desde el componente epistemológico de la categoría de comunicabilidad y apertura desde los postulados de John Hick y Raimon Panikkar. Por último, se presentan los aportes de la ERE al pluralismo religioso a partir de un itinerario pedagógico apoyado en la interdisciplinariedad.

\section{La ERE: desarrollo histórico del siglo XIX}

Precisar el desarrollo de la ERE, no es una tarea fácil de emprender, pues desde su comprensión primigenia siempre ha estado relacionada con los ambientes eclesiales y con un ingreso en la malla curricular que favorecía en cierta medida a la religión, no tanto como una formación integral, sino por una marcada confesionalidad cristiana católica que se vió patrocinada por la política. Por lo tanto, presenta un gran reto al respecto dar un juicio sobre la naturaleza y desarrollo de la ERE (Azevedo, 2018, citado en Botero y Hernández, 2018).

Por otra parte, López (2014) afirma:

La educación religiosa fue uno de los temas que estuvo siempre presente en la agenda política de los gobernantes, ya que era una forma de mantener cierto dominio y control en gran parte de la sociedad, lo que generó conflicto y tensión en la sociedad, de alguna forma esta inestabilidad llevó a la educación religiosa, a no estar definida en comparación con otras áreas del conocimiento. (p.18)

La historia corrobora que la ERE se ha gestado en medio de esferas de orden político, social y eclesial, que la han llevado en cierta medida a estar "sujeta a una serie de leyes que a través de la historia han ido cambiando y generando nuevos discursos en torno al respeto por los derechos y diferencias religiosas" (López, 2014, p.13). A propósito, también Meza et al. (2011) afirma que "la Educación religiosa Escolar (ERE) ha cumplido históricamente un papel en Colombia que no se puede reducir a los contenidos dictados en clase, sino que se tiene que comprender de una manera más amplia” (p. 39).

Releer la historia de la educación religiosa en Colombia le da una especial significación a este estudio, pues en la comprensión de la naturaleza de la ERE, no es posible dejar a un lado la lucha de poder entre el Estado y la Iglesia, representados en los partidos conservador y liberal, generando unas tendencias en la educación que influyeron en cierta medida en su configuración. Acerca de esto, Guerrero, Andrade y Castro (1999) señalan: 
En 1822 la creación de la Dirección de la Enseñanza Pública que establece la educación pública, obligatoria y laica, en aplicación de la Ley de Educación aprobada por Simón Bolívar, más conocida bajo el nombre de Plan de Estudios Nacional de Santander, fracasa por la escasez de recursos financieros que impide la contratación de maestros. Es así, como la presencia de las congregaciones religiosas es indispensable al menos hasta 1837. (Citado en Andrade, 2011, p. 166)

Desde 1839, la enseñanza genera entonces una confrontación política e ideológica marcada por dos tendencias antagónicas: por una parte, la conservadora que solicitaba continuar la educación por parte de las congregaciones religiosas $y$, por otra parte, la tendencia liberal que buscaba una educación de espíritu laico y de carácter público alejada del sistema eclesial. Es de vital importancia destacar que el cambio de tendencia acompañado generalmente por una guerra civil marcaba el espíritu educativo desde sus perspectivas e ideologías. Ya en 1844 por medio del presidente Ospina Rodríguez y su reforma educativa se impuso la tendencia conservadora, pero seis años más tarde en 1850, el gobierno de turno de carácter liberal, liderado por José Hilario López, hace efectiva la libertad de enseñanza convirtiendo en colegios nacionales las universidades (Andrade, 2011).

En 1870, con la creación del DOIP (Decreto Orgánico de Instrucción Pública) por parte del Gobierno liberal, se dio pie al enfrentamiento más agudo entre las dos soberanías: la del Estado liberal y la Iglesia Católica. La Iglesia hizo una gran oposición señalando que el deber ser de la educación era formar cristianos con virtudes capaces de asumir el rol de ser ciudadanos, pero desde los principios religiosos y no desde la educación laica que se saltaba la dimensión de las virtudes de las personas. El clero incitó a que se dieran grandes contiendas hasta persuadir a los padres para que no enviarán a sus hijos a las escuelas, descalificando así el DOIP como protagonista de la desmoralización y de la pérdida de las creencias re- ligiosas. El enfrentamiento, que fue más allá de lo retórico, mereció ser llamado la Guerra de las Escuelas dado que tuvo un impacto nacional (18761877). Esta situación la describe Alarcón (2012) como "una cruzada destinada a recuperar para la población la instrucción religiosa, así como los valores y tradiciones católicas que habían caracterizado a la sociedad colombiana” (p. 93).

No se trataría objetivamente de la existencia de dos partidos sino de dos caminos, uno tradicionalista y otro modernista para la construcción de la nación (Alarcón, 2012). Sin embargo, Giraldo (2009) expresa que el conflicto tenía intereses de fondo también económicos, pues el liberalismo buscaba más allá de formar una ciudadanía moderna, forjar ciudadanos productivos y así impulsar económicamente al país. Es entonces vital destacar no solo el alcance político y religioso del tema educativo, sino el económico que respondiera a un sistema capitalista con una nueva política (citado en López, 2014).

A lo largo de los años, el poder político fue pasando de un bando a otro, es decir, el poder por un tiempo lo tenían los conservadores y otro tiempo los liberales con la duración inestable en distintos períodos; por ejemplo, los liberales establecieron la no interferencia del gobierno en la educación religiosa, para así salvaguardar sus intereses cuando estuvieran fuera del turno de mandato. Un testimonio al respecto lo narra Alarcón (2012) escribiendo: "uno de los aspectos más controvertidos del Decreto Orgánico de Instrucción Pública fue el de la educación laica, a la cual se refería el artículo 36, al establecer «que el gobierno no interviene en la instrucción religiosa»" (p. 81).

Pero la Iglesia no se quedaría con los brazos cruzados y junto con ella la tendencia conservadora, buscaría no solo recuperar el poder, sino salvaguardar la educación de la laicización. En 1870 surge entones un marco legal para la secularización de la educación que continuaba con el proceso de la Constitución de 1851 y que determinaba la 
separación del Estado y la Iglesia, con ratificación en la Constitución de 1853 y ordenamiento jurídico en 1863, generando una inquina casi fanática del partido conservador y de la Iglesia (Alarcón, 2012). Todos los intentos liberales para la construcción de un Estado laico encontraron una gran barrera por parte de los conservadores y de la Iglesia, pues la sociedad colombiana de la época estaba marcada por las tradiciones religiosas. Lo anterior tiene validez si se recuerda que a finales del siglo XIX se da la inserción del proyecto político de la Regeneración, que asignaría una Constitución centralista proclamada en nombre de Dios, fuente suprema de toda autoridad. Ya la firma del concordato entre el Estado colombiano y el Vaticano en 1887 en el artículo 53 instauraba la independencia de la Iglesia en sus asuntos internos y el ejercicio de su poder espiritual sin necesidad del poder civil (Alarcón 2012).

Aún vigente el concordato, la pugna de poderes hoy continúa ya no entre la Iglesia y los liberales, sino entre los distintos partidos políticos. Sin embargo, la ERE se ha ido matizando a finales del siglo XX por un marco legal que le ha dado su actual situación en Colombia. En el siguiente numeral se precisará la legislación educativa de la ERE a partir de la Constitución de 1991 y como se puede hablar de una incipiente, pero significativa transición, de una ERE ligada a la confesionalidad a una ERE como disciplina desde la pluralidad que lleva a la trascendencia, como elemento esencial en el ser humano.

\section{La ERE a finales del siglo XX e inicio del XXI y el marco legal de transición de la confesionali- dad hacia la pluralidad}

Como se puntualizó en el apartado anterior, la ERE en Colombia ha estado orientada por pará- metros de los partidos políticos de turno que han dirigido al Estado, es decir, los conservadores y los liberales, pero hablar de confesionalidad, equivale a rotular a la Iglesia cristiana católica, apoyada en el siglo anterior por el grupo político conservador. Al respecto Botero y Hernández (2018) expresan:

Durante los períodos de conquista, de colonización, de patronato español, de independencia y hasta la Constitución de 1991, la educación religiosa escolar se comprendió desde los paradigmas cristianos católicos: La evangelización y la pastoral. En efecto los contenidos eran dogmas; el método, la memorización, y la finalidad, la fundamentación de la fe cristiana. (p. 24)

Hablar hoy de ERE, más allá de una confesión religiosa, significa dar valor a la globalización que señala una nueva dirección, es decir, la pluralidad religiosa que se convierte en una nueva herramienta de apertura y respeto hacia a las demás creencias religiosas, generando así una educación incluyente que habla de divinidad, no ya desde una nominación cerrada y dogmática, sino desde la trascendentalidad donde se expresa una apertura al totalmente Otro, desde diferentes experiencias religiosas. Esta nueva manera de pensar la ERE es posible gracias a la legislación colombiana, especialmente en las últimas décadas, que de una u otra manera superó los "paradigmas confesionales que se vincularon a la tarea docente" (Botero y Hernández, 2018, p. 13). Fue entonces la normatividad legal de la República de Colombia la que proporcionó luces a la marcada ambigüedad de la ERE, especialmente partiendo de la Constitución de Colombia de 1991 hasta la actualidad (Botero y Hernández, 2018).

Así el paso fundamental de la confesionalidad a la trascendentalidad ${ }^{4}$ se encontraba en etapa embrionaria en la Constitución de 1991 del

\footnotetext{
${ }^{4} \mathrm{La}$ trascendentalidad aquí se comprende como una dimensión del ser humano que es vital para dar respuesta a los interrogantes más profundos de su existencia inicial y final. Es un acontecimiento que implica salir de sí mismo para buscar el sentido de su existencia no precisamente hacia una determinación nominal distinta de él, sino a cualquier experiencia de sentido diverso a él. Víctor Frankl, (2004) señala "(...) cuanto más se afana el hombre por conseguir la autorrealización más se le escapa de las manos, pues la verdadera autorrealización solo es el efecto profundo del cumplimiento acabado del sentido de la vida. (...) la autorrealización no se logra a la manera de un fin, más bien como el fruto legítimo de la propia trascendencia" (p. 133).
} 
Estado colombiano, la cual determina como un derecho la libertad religiosa señalando: "Se garantiza la libertad de cultos. Toda persona tiene derecho a profesar libremente su religión y a difundirla en forma individual o colectiva" (Art 19). Así, la libertad de cultos marcaba el fin, si bien es cierto no absoluto, pero si daba límites a la centenaria confesionalidad del cristianismo católico, dando apertura a otras experiencias religiosas que también aportarían a la educación sus parámetros doctrinales y que más tarde influirían en la posterior legislación educativa respecto a la ERE.

Al respecto del marco legal de la ERE, Botero y Hernández (2018) afirman:

Está elaborado, con base en: la Constitución Política Colombiana, en la Carta de Navegación de todos los procesos ciudadanos, en la Ley General de Educación 115 de 1994, y en las leyes, los decretos y las directivas que regulan la ERE en Colombia: Ley 133 de 1994, Decreto 1278 de 2002, Directiva Ministerial 002 de 2004 y el Decreto 4500 de 2006 (p. 18-19).

La ley 115 de 1994 que direcciona todo el sistema educativo colombiano, habla de la ERE en el artículo 23 ubicándola en el sexto puesto de las áreas obligatorias; sin embargo, se aclara que ninguna persona podrá ser obligada a presenciar este espacio académico. Se debe precisar que, frente a la ERE, hay una gran ambigüedad pues tan solo un artículo después, en el 24 se determina que es un derecho. Lo más trascendental de esta ley es precisamente el calificativo de espiritual que se repite en tres ocasiones en los artículos 5 numeral 1, en el artículo 15 y finalmente el artículo $16 \mathrm{~h}$. De esta manera, se determina la dimensión espiritual como la naturaleza de educación religiosa. En síntesis, esta ley se debate entre la obligatoriedad y la libertad de la ERE (Moncada y Barreto, 2018).

La ley 133 de 1994 explicita el artículo 19 de la Constitución de 1991 que habla de la libertad religiosa como derecho de los ciudadanos señalando así el paso de la mono-confesionalidad y abrién- dose a la experiencia del pluralismo y la multiculturalidad. El artículo 6 en el inciso g, expresa que se puede dar la enseñanza e información religiosa ya sea por medio escrito $u$ oral solo a quien desee (Botero y Hernández, 2018, p. 20).

Estas legislaciones, no solo dieron un paso de la confesionalidad al pluralismo religioso y de este a las trascendentalidad, fundamentado por la libertad de la persona humana, sino que también dio nuevas luces al campo pedagógico y a la misión del docente de ERE. A propósito, escribe Botero y Hernández (2018): "para realizar dicho ejercicio de enseñanza o trasmisión es necesario poseer un "Certificado de Idoneidad" que proceda de una iglesia o religión a la cual pertenezca" ( $p$. 20). Lo anterior permite intuir, que el docente de educación religiosa no debe ser necesariamente un profesional o licenciado y que su misión en las escuelas está orientada en las directrices de la comunidad religiosa a la que pertenezca. $\mathrm{Al}$ respecto también se puede decir que la función del docente de ERE consistió en "vigilar la trasmisión de los preceptos de un sistema religioso, ya que la idoneidad de la enseñanza no parte de un título como tal, sino de una certificación expedida por la Iglesia a la cual esté ligada la institución Educativa" (Botero y Hernández, 2018, p. 20).

Después de ocho años, el Decreto 1278 emitido el 19 de junio de 2002, en el artículo 21, señala los tres grados de escalafón docente que son normalista, licenciado y doctor. Con lo anterior queda en vilo la idoneidad del docente de ERE, pues hace años se había hablado de un certificado de idoneidad notándose nuevamente una clara ambigüedad acerca de la profesionalización del docente en ERE. (Botero y Hernández, 2018). Dos años más tarde, la Directiva Ministerial 002 de 2004 señala a la ERE como un espacio académico obligatorio en las instituciones educativas estatales y no estatales, pues considera esta como un área fundamental en la formación y el conocimiento. Esta asignatura se realizará desde la elección de la formación de los padres o tutores de los estudiantes y desde los con- 
venios con las distintas confesiones. Estás además presentaran los programas del plan de estudio. La directiva también legisla sobre la no obligatoriedad y hace un llamado a los docentes a no practicar el proselitismo y a orientar sus clases en la intensidad horaria fijada por el PEI. También resalta la importancia de la formación permanente en esta área.

Por otra parte, el Decreto 4500 del 19 de diciembre de 2006 realiza una alocución sobre los fundamentos de la ERE, repitiendo elementos de la directiva del 2002 y especificando otros aspectos relevantes como el ámbito de aplicación en los niveles de preescolar, educación básica y media. También se explicita la importancia de la concepción integral de la persona humana y su dimensión trascendente.

Según la panorámica histórica y legal que se ha desarrollado de la ERE, se pude señalar que la confesionalidad y la no confesionalidad, siguen vigentes en los distintos establecimientos, pues la ambivalencia de las leyes y el principio de la libertad religiosa han hecho de la ERE un área si bien es cierto vital para la educación de la integralidad del ser humano, en este caso particular de los estudiantes, también hoy se puede ver como señala Botero y Hernández (2018): "una evolución teórica y experiencial de la ERE dentro de las lógicas de la escuela" (p. 24). Lo cual equivale a definir aún con cierta preocupación que la educación religiosa en Colombia sigue siendo, a pesar de todo, una paradoja que amarra cualquier intento de fundamentación con los sistemas religiosos que rigen las escuelas.

\section{Hacia una definición de pluralismo religioso}

En el recorrido histórico realizado en esta investigación se evidencia que en Colombia ha existido una marcada confesionalidad, manifestada con un solo rostro, el de la Iglesia cristiana católica. Fue solo hasta la Constitución Política de 1991, cuando se pudo expresar el derecho a la libertad de cultos, generando así un significativo avance en lo que se podría llamar un país plural, no porque no lo fuera de facto, sino que la legislación no había hecho un pronunciamiento oficial.

En este sentido, Colombia se destacan por ser un país pluriétnico; cómo olvidar, por ejemplo, las culturas indígenas y las descendencias de los negros traídos como esclavos por los españoles que generaron con los siglos la llamada cultura afrodescendiente, la presencia de la religión católica a partir de la Conquista y fortalecida en la colonia, y finalmente, la presencia del cristianismo protestante. Hoy todo este influjo hace del tejido social un auténtico fenómeno plural que coloca grandes retos a la ERE marcada por mucho tiempo por la confesionalidad cristiana católica y que pide ser desde la normatividad legal transformada en pro de la pluralidad (Botero y Hernández, 2018).

La ERE, si desea tener una episteme actual y cualificada para la formación de los estudiantes, debe comenzar por considerar la pluralidad social y religiosa vital en su aporte a la trascendentalidad e integridad del ser humano desde la pedagogía. Por lo tanto, se hace necesario estudiar este fenómeno socio-religioso del pluralismo para poder responder a los retos de la Colombia del siglo XXI. Al respecto Botero y Hernández (2018) afirman que "las expresiones culturales vivenciadas por las comunidades originarias del territorio nacional - ricas en sapiencias acerca de la dimensión espiritual del ser humano y su importancia para la comunidad - deberían tenerse en cuenta como los primeros conocimientos de educación religiosa" (p. 24).

Para comprender qué es el pluralismo religioso conviene considerar las Palabras de María Coy (2010) cuando afirma que "hoy todo es plural, diverso, diferente" (citado en Botero y Hernández, 2018 , p. 27). Este ejercicio hermenéutico se realizará a partir de la reflexión de dos pensadores contemporáneos, John Hick y Raimon Panikkar, pues sus propuestas son hoy para la ERE un hori- 
zonte de apertura a un mundo multicultural y plural.

En primer lugar, se encuentra el británico John Hick (1922-2012), considerado como uno de los máximos representantes del pluralismo religioso. Este filósofo plantea desde la teoría kantiana del noúmeno y el fenómeno el principio del ver y percibir, es decir, desde un subjetivismo cognoscitivo. Al respecto de este principio Meléndez (2015) explica que "percibir lo absoluto es siempre percibirlo como de esta manera o de aquella otra como personal, o como impersonal, como todopoderoso o misericordioso, como Vishnú o como Shiva, como el Dios Único o como la Sagrada Trinidad" (p. 6). Comprender el pensamiento de Hick requiere una reflexión tripartita, pues existe una realidad trascedente (metafísica), que al revelarse es conocida por alguien (epistemología) $\mathrm{y}$, por lo tanto, cualquier noúmeno religioso (teología) no podrá expresarse, sino en términos de lo real experimentado desde las percepciones humanas (Meléndez, 2015).

Este panorama filosófico sirve para argumentar sobre el pluralismo religioso. Afirma Meléndez (2015): "Hick sugiere aplicar esta perspectiva a nuestra propia percepción de lo Real mediante la distinción entre el noúmeno real, lo Real an sich, y lo Real como humanamente percibido de diversas formas, aplicado al ámbito del fenómeno divino" (p.7). Lo anterior en términos más asequibles equivaldría a decir que "cada persona, pues, percibiría a Dios desde su propia franja religiosa y perceptiva personal" (Meléndez 2015, p. 8). Así, en el pluralismo religioso juega un papel primordial la experiencia humana que es diversa en todas las culturas y plural en su subjetividad, por lo tanto, se comprendería que "todas las religiones del mundo (...) como varias acumulaciones y logros de respuestas humanas a lo Real en sí, de forma que todas ellas habrían de estar a la par las unas en relación con las otras" (Meléndez 2015, p. 8).

Acerca de Hick comenta Bobadilla (2006):
La revolución copernicana que propone Hick consiste en un cambio de paradigma (...) después de haber creído durante siglos que el sol giraba alrededor de la tierra, se descubrió, gracias a Galileo y Copérnico, que en realidad es la tierra la que gira alrededor del sol (...) Incluye un cambio del dogma según el cual las religiones gravitan alrededor del cristianismo y exige reconocer que Dios es el centro alrededor del cual gravitan todas las tradiciones religiosas, incluyendo la nuestra. Se pasa de una visión eclesiocéntrica o cristocéntrica a una visión teocéntrica. (p. 70-71)

De esta manera, la confesionalidad cristiana católica queda relegada dando paso al teocentrismo donde sí sería posible la experiencia de un diálogo interreligioso. Hick (1980) en su célebre obra God has many names señala: "Debemos aceptar la necesidad de elaborar una nueva comprensión de nuestra fe, no como la única, sino como una de varias" (Citado en Bobadilla, 2006, p. 64). Así el aporte de Hick brinda herramientas para dar el paso de la confesionalidad a la pluralidad no de dioses, sino de experiencias del único Dios.

En segundo lugar, se encuentra Raimon Panikkar (1918-2010), filósofo de la religión y protagonista del diálogo religioso por su vinculación a cuatro credos religiosos, lo convierte en el gran exponente del pluralismo religioso (Meléndez, 2015). John B. Cobb (1996) acerca de Panikkar comenta que "nadie luchó con más coraje con el problema del pluralismo como Raimon Panikkar. Este no es para él sólo un problema teórico sino más bien práctico (...). Este es, además, un profundo problema existencial" (Citado en Meléndez, 2015, p. 11). Meléndez señala también que para Panikkar "la realidad es una y múltiple, pero todo en el seno de un único ser, en un universo en el que no se debe dividir entre materia y espíritu" (2015, p. 10). El punto de encuentro con Hick está en la relatividad de la experiencia que tiene el ser humano con lo Real, pero supera el dualismo kantiano asumido por Hick de Noúmeno y de fenómeno ya que considerada la realidad como 
una experiencia que integra tres dimensiones: la sensible, la racional y la mística (Meléndez, 2015).

La interculturalidad se convierte entonces en una categoría clave para comprender el pensamiento de Panikkar acerca del pluralismo religioso que tiene como fundamento la experiencia humana del conocimiento de la realidad presente en diversas culturas y nunca agotado en su totalidad por ninguna (Meléndez, 2015). Lo anterior es a lo que Panikkar llamaría "la filosofía imparativa, una forma de pensamiento que pretende, precisamente, dar la bienvenida a la diversidad humana como parte intrínseca de la existencia de los seres humanos" (Meléndez, 2015, p. 11). La pretensión del postulado de Panikkar era generar un diálogo con las otras religiones en donde no se procurara el convencimiento dogmático, sino una cooperación basada en el mutuo entendimiento para buscar una respuesta nacida del concurso de todos. Para este defensor del pluralismo religioso, el hombre debe estar abierto a acuerdos interculturales. Explicando la obra célebre de Panikkar (1979) Myth, Faith and Hermeneutics, Meléndez (2015) dice que "la sabiduría no consiste en una visión monocromática del mundo, o una abstracción infinita, sino en una loable y rica variedad de colores llenos de vida" (p. 11). Al contrario de John Hick, para Panikkar la argumentación humana es limitada y por ello, se hace necesario el esfuerzo conjunto de conocimiento de los distintos credos y luego acogerlos a todos (Meléndez, 2015).

El pluralismo religioso entonces se podría definir como una experiencia humano-religiosa en donde la diversidad y pluralidad de la experiencia de Dios, de lo Real, del totalmente Otro, debe llevar al auto-reconocimiento y conocimiento de las otras religiones y la posibilidad de un diálogo incluyente y no excluyente de los diversos credos. En palabras de Sánchez (2008) se trata de una experiencia religiosa desde diversos puntos de vista que lleve "a descubrir el encuentro entre creyentes de distintas religiones, en este mundo plural, como un verdadero lugar teológico" (Citado en
Restrepo, 2015, p. 449).

De esta manera, el pluralismo religioso se convierte no solo en un tema de actualidad que coloca al día la malla curricular de la ERE, sino en una actitud de vida que requiere, escucha, respeto, inclusión, reconocimiento de la diversidad y por ende una plataforma de auténtico humanismo que influiría en la formación integral y espiritual del ser humano que respondería al urgente llamado del mundo que pide respuestas capaces de guiar al hombre de hoy desde una apertura que supere la antigua concepción anquilosada y los esquemas repetitivos que están lejos de los hombres y las mujeres del tiempo actual. (Consentino, 2012). Vistas así las cosas la ERE no solo debe aportar al plan curricular de las escuelas, sino a crear una auténtica cultura de inclusión que eduque a las generaciones presentes y futuras para no vivir la religación sin un humanismo que abandone el egocentrismo de la falsa confesionalidad y se abra a la experiencia de la humanidad plural y diversa.

\section{Aportes de la ERE a la promoción del plu- ralismo religioso}

No se puede negar que la globalización ha hecho posible tomar conciencia que el mundo siempre había sido plural y diverso y ante esta visión Colombia no es la excepción. En el documento, Colombia una nación multicultural su diversidad étnica, emitido por el Departamento Administrativo Nacional de Estadística (DANE) se indica que:

El país es reconocido como pluricultural y multilingüe, dada la existencia de 87 etnias indígenas, 3 grupos diferenciados de población afrocolombiana y el pueblo ROM o gitano; se hablan 64 lenguas amerindias, el bandé, lengua de los raizales del Archipiélago de San Andrés, Providencia y Santa Catalina, el palenquero, lengua criolla de las comunidades de San Basilio de Palenque (...) y el Romaní o Romanés lengua Rom. (2007, p. 9) 
La educación no es ajena a este patrimonio nacional y por ello la ERE como área de conocimiento se encuentra delante de un gran reto, pues ante este panorama de la diversidad y la interculturalidad está llamada a ver en estas categorías una oportunidad para formar a los estudiantes en el reconocimiento de la pluralidad y enriquecer la dimensión espiritual y trascendental de la persona humana. Partiendo entonces de la definición del pluralismo religioso como una categoría de comunicabilidad intercultural, se propondrán desde la ERE algunos aportes que, fundamentados en las experiencias de algunos teóricos de la educación, contribuyan a la promoción del pluralismo religioso sin perder de vista el marco legal de la educación y otros elementos esenciales que en sintonía con los retos de hoy, le permitan a la ERE dar una respuesta efectiva y afectiva a la formación de los estudiantes como auténticos seres humanos.

Los aportes estarán enmarcados bajo un itinerario que consta de los siguientes pasos: en un primer momento, se tendrá en cuenta a los protagonistas, pues no se puede perder de vista que la educación es un proceso personal y personalizador. En un segundo momento, se propondrá un método, pues sin él no sería posible un proceso de formación serio y comprometido. En tercer lugar, es necesario conocer qué clase de conocimiento quiere alcanzar la ERE a través de la promoción del pluralismo religioso y la importancia de la transdisciplinariedad, de tal manera que entonces se pueda trazar un trabajo pedagógico en tres importantes dimensiones humanas que serían herramientas para la promoción del pluralismo religioso: la humanización, la interculturalidad y la comunicabilidad.

El primer paso involucra a los protagonistas del proceso educativo-formativo, es decir, a toda la comunidad educativa (directivos, docentes, estudiantes y padres de familia), de tal manera que la ERE pueda, desde su epistemología y como formadora de la integridad del ser humano, revalidar eficazmente el papel protagónico de los hacedores de la educación en el contexto del pluralismo religioso, de lo contrario, se camina a un inminente fracaso de frente al ideal de esta investigación. Acerca de esto Almeida (1995) expresa que "debe haber intercambio e integración entre padres, maestros y educadores, para que la enseñanza interdisciplinar sea coherente (...) En la sociedad pluralista, tenemos todos que ayudar al niño, desde el inicio, a tener respeto y estima a los demás" (citado en López, 2014, p. 82). Esta tarea cooperativa se convierte ya en una plataforma de encuentro entre la pluralidad de experiencias de fe y religación en donde no sería una quimera los valores de la inclusión y la tolerancia capaces de crear en el tejido social una transformación que llame a vivir el pluralismo religioso como una experiencia de interculturalidad humana, social y trascendente.

El segundo paso es vital y se trata de establecer el método a utilizar por la ERE para la promoción del pluralismo religioso. Freire (2005) comenta que "no puede haber palabra verdadera que no sea un conjunto solidario de dos dimensiones indicotomizables, reflexión y acción. En este sentido (...) una educación que promueva el valor de la palabra promueve el respeto por la diversidad y el pluralismo" (Citado en López, 2014, p. 72). Por ello la ERE está llamada a ser una reflexión capaz de tocar la realidad personal e integral de los estudiantes y transformarla. Se trata aquí no de teorizar, sino de construir un conocimiento capaz de influenciar, en el sentido positivo del término, a los estudiantes, de tal manera que estos sean capaces de construir su historia y aporten a la historia un sentido de libertad frente a las abominaciones realizadas en el nombre de la homogeneidad, de lo igualatorio, de lo que tiene un solo común denominador. En este sentido, Pérez (2017) propone, en el marco del pluralismo, una relación articulada entre ERE y teología en la que no se debe:

Absolutizar las comprensiones de lo divino (...), debe atender a la escucha rompiendo con las hegemonías, haciendo opción por los pobres 
y necesitados, interpretando los signos de los tiempos para enriquecer su quehacer práctico y conceptual con los aportes de las distintas comprensiones de lo divino y de las ciencias del hombre, siendo más cercana a las dinámicas históricas de los pueblos y teniendo como parámetro de funcionamiento y de comprensión siempre en función de la persona humana. (p. 24)

El anterior método busca alcanzar un resultado cognitivo, es decir, un conocimiento que en verdad impacte la vida de los estudiantes en donde la espiritualidad ${ }^{5}$ está llamada a ser transversal en la ERE. A propósito, Perilla, Ramírez y Agudelo (2019) afirman que:

La espiritualidad ha dejado de ser una prioridad en la formación religiosa, al igual que la tolerancia en la formación ética; argumento que va en línea con la perspectiva sociocultural de la educación, en donde los valores absolutos tienden a relativizarse quedando a libre albedrío su escala y jerarquía. (p. 22)

Ante este cuadro de relativización, la ERE debe proponer la inteligencia espiritual ${ }^{6}$ como clave en la educación de las subjetividades de los diferentes credos orientando el proceso educativo desde los valores del amor, la compasión y el bien que engendran la felicidad y la paz. La inteligencia espiritual entonces sería una derivación de la inteligencia emocional (Goleman 2002; citado por Fragoso, 2015). De esta manera, se concebiría la inteligencia espiritual como generadora de una sociedad axiológica. Zohar y Marshall (2001) explicando la inteligencia espiritual señalan que esta es una pilastra fundamental a través de la cual se determinan elementos esenciales de la vida como lo son las visiones, las esperanzas y los valores (Citado por Perilla y Machado, 2020). Desde las anteriores comprensiones la inteligencia espiri- tual sería la clave para una ERE que alejada de la mono-confesionalidad se abra a la experiencia y al horizonte enriquecido del pluralismo religioso.

No es posible este ambicioso ideal pedagógico sin un compromiso holístico. Para ello se propone la transdisciplinariedad como parte fundamental de este itinerario. Morin (1999) señala que "el conocimiento pertinente debe enfrentar la complejidad (...) en efecto hay complejidad cuando son inseparables los elementos diferentes que constituyen un todo" (p. 38). Esta apreciación es oportuna, pues no se puede seguir pensando en una ERE aislada del pluralismo religioso o, peor aún, como un área diversa de la integridad académica de los estudiantes. Hablando de la transdisciplinariedad Morín (1999) señala:

Este concepto es importante en la medida en la que ayuda potencialmente al estudiante a reconocer que, si bien de manera pedagógica se reducen algunas cosas a conceptos básicos, en la realidad no podemos hacer esto, sino que los conocimientos adquiridos están conectados al igual que un circuito. (Citado en López, 2014, p. 56)

Para la ERE es apropiado este concepto, pues lleva al estudiante a la reflexión de un mundo del cual él no puede sustraerse, sino al cual debe abrirse en el descubrimiento de lo diverso que enriquece la vida y elimina el individualismo generando una comprensión de la alteridad como riqueza. Siendo así, la ERE puede a través del pluralismo religioso propiciar la educación en tres dimensiones: la humana, la intercultural y la comunicativa. Estás dimensiones no se encuentran aisladas, sino integradas en la persona humana, pues sin un reconocimiento de la propia humanidad y la de los demás, no sería posible una cultura del encuentro con otras realidades y experiencias,

${ }^{6}$ Respecto a este punto, conviene retomar la aproximación epistemológica propuesta por Naranjo y Moncada (2019) sobre el significado de la espiritualidad, pues con frecuencia se suele asumir con sentido semántico casi equivalente el concepto de espiritualidad con otros afines como fe, religión, experiencia religiosa y confesionalidad.

${ }^{5}$ Para profundizar en la relación entre inteligencia espiritual, espiritualidad, escuela y ERE, se sugiere retomar los textos de Moncada (2020) y López (2019). 
imposibilitando así una comunicación que se expresa a través del diálogo respetuoso.

La ERE aporta entonces en los estudiantes una auténtica formación en la dimensión humana, dándole al estudiante la capacidad de una inteligencia espiritual capaz de permear su propia humanidad, pues sin esta no puede haber una verdadera religación. Así se pasa de la religación sin humanización a una religación capaz de ver al totalmente "Otro", desde el rostro de los otros. Una ERE que descarta lo humano y por ende los valores de la fraternidad, la aceptación, la tolerancia y de la apertura a la diversidad fracasaría y haría de su deber ser una auténtica quimera. Así la dimensión humana es la base para una educación religiosa que promociona el pluralismo.

Otro componente importante que aporta a la promoción del pluralismo religioso es la interculturalidad, que puede ser comprendida como una categoría que se ha desarrollado aceleradamente por medio del fenómeno de la globalización, de hecho, en las escuelas se trata de un escenario pedagógico que no puede ser ignorado. Algunos autores aportan elementos que promueven la transformación del aula de clases en una óptima plataforma para desarrollar una ERE que impulse el pluralismo religioso y que sea capaz de promover "procesos de interculturalidad a favor de la educación y el desarrollo de la dimensión espiritual, en el contexto propio de la formación integral de la personalidad, no de orden meramente cognitivo, sino experiencial" (Hernández y Botero, 2018, p. 33).

La ERE debe ver el pluralismo como parte de la interculturalidad, si bien es cierto no como su único horizonte de trabajo, si como un nuevo areópago de inclusión que supera la exclusión de la confesionalidad y da una nueva perspectiva de comprensión de la religión como fenómeno humano y de alteridad. Lo anterior debe tener como base el diálogo, pues un encuentro que no supere la comunicación unidireccional generaría una cultura yuxtapuesta que, en lugar de unir, causa su autoafirmación absoluta y escéptica anteponiéndose a la riqueza de la interacción con diversas experiencias humanas y provocando una división que niega la sociabilidad de la condición humana.

Por último, se encuentra la dimensión de la comunicabilidad que solo es posible desde la base del reconocimiento de lo humano e intercultural, pues solo el hombre tiene la capacidad de comunicarse. Con relación a esto López (2014) señala que la ERE "sirve esencialmente para «conocerse a sí mismo conociendo», que la educación religiosa escolar no es una manera de absolutizar todo y acabar con las interrogaciones de la vida. La educación religiosa escolar es una manera de vivir viviendo" (p. 57). De esta manera, el conocimiento tiene como base el reconocimiento que solo es posible desde una perspectiva dialógica que sea capaz de compartir experiencias significativas de religación en la mediación de valores como la tolerancia, el respeto a la diversidad social, cultural y religiosa, donde no haya conflictos religiosos, ni discriminación de cualquier índole sino una afirmación de lo religioso a través de lo interreligioso. Así la experiencia religiosa en la medida que se abre al diálogo se afirma en su identidad no excluyendo las demás realidades o credos religiosos, sino en la apertura y acercamiento donde lejos de anularse o empobrecerse se enriquece (Magendzo, 2007).

La ERE entonces tiene la posibilidad de promocionar el pluralismo religioso no como fenómeno sociocultural de la humanidad de hoy, sino como experiencia de convivencia que no se puede desconocer ni en las aulas de clase, ni en la vivencia de las relaciones humanas. Una miope comprensión de la religión no puede seguir siendo el pretexto para humillaciones, discriminaciones y bullying en el ambiente escolar, mucho menos de guerras continentales y locales, sino que desde la ERE se puede propiciar una dinámica de religación con la trascendencia que no olvide la humanización, la interculturalidad y el diálogo 
ya que el pluralismo religioso es la pluralidad de manifestaciones del totalmente Otro en la subjetividad de la persona humana y la multiplicidad de culturas en las que viven los seres humanos y desde la cual es posible escribir una nueva historia de la humanidad.

\section{Conclusiones}

Las grandes transformaciones que ha vivido el mundo de hoy exigen una educación contextual, es decir un proceso de conocimiento en donde los docentes y estudiantes generen un conocimiento propositivo y comprometido con los retos de la sociedad de hoy. La ERE, no puede ser ajena a estas grandes transformaciones y cambios de la sociedad y por lo tanto, desde el impulso que las leyes han generado en la educación nacional, ésta área del conocimiento se convierte en una herramienta de inclusión de la persona humana desde la pluralidad de creencias y la diversidad cultural.

La ERE tiene en frente un tema tan espinoso como la religión y las creencias, la oportunidad histórica de trabajar por un país y una sociedad más inclusiva que promocione desde los valores del respeto, la tolerancia y la paz, un legítimo diálogo entre las personas de distintas creencias que sean capaces no solo de conocer la diversidad de la fe de los demás, sino de generar acciones en orden a una auténtica promoción del pluralismo religioso como categoría de humanidad, interculturalidad y comunicabilidad. De esta manera, la ERE tiene por vocación natural y epistemológica ir más allá de un adoctrinar, a generar en las futuras generaciones competencias en pro de una sociedad que acogiendo las diferencias sociales culturales y religiosas, trabaje por un mundo más humano y fraterno.

\section{Referencias bibliográficas}

Alarcón, L. (2012). Dios y la religión o el reino de la autoridad laica. Educación, Iglesia y Estado en el Caribe colombiano, 1863-1879*.
Historia Caribe - Volumen 7, (21), 75-108. Andrade, M. (2011). Religión, política y educación en Colombia. La presencia religiosa extranjera en la consolidación del régimen conservador durante la Regeneración. Historelo Revista de historia regional y local Volumen 3, (6), 154-72.

Bernate, J., Gómez, B., Herrera, P., Machado, M., Mosquera, D., Perilla, A., Romero, E., Sierra, O y Varela, O. (2020). Innovación educativa desde la praxis y formación docente. Colección: Resultado de Investigación. Volumen No. 1. Primera Edición 2020. Editorial EIDEC.

Bobadilla, D. (2006). La cristología teocéntrica de John Hick. Revista Iberoamericana de Teología, (3), 63-91.

Botero, C. y Hernández, A. (Ed.). (2018). Aproximaciones a la naturaleza y fundamentos epistemológicos de la Educación religiosa Escolar. Bogotá: Unicatólica.

Cosentino, F. (2012). Sui sentieri di Dio Mappe della nuova Evangelizzazione. Milano: San Paolo Edizioni.

Constitución Política Colombiana de 1991.

DANE. (2007). Colombia una nación multicultural su diversidad étnica. Departamento Administrativo Nacional de Estadísticas. Recuperado de http://www.dane.gov.co/files/ censo2005/etnia/sys/colombia_nacion.pdf

Fragoso, R. (2015). Inteligencia emocional y competencias emocionales en educación superior, ¿un mismo concepto? Revista Iberoamericana de Educación Superior, 6, (16) ,110-125.

Frankl, V. (2004). El hombre en busca del sentido último. Un psicólogo en un campo de concentración. Barcelona, España: Herder.

López, C. (2019). La espiritualidad en el aula: una experiencia situada y sentida. Revista Cultura, L(280). 19-21. Recuperado de https://conaced.edu.co/themencodepdf-viewer/?file=https://conaced.edu.co/ wp-content/uploads/2020/01/ConacedEdi-280-3-1.pdf 
López, J. C. (2014). La educación religiosa escolar en Colombia: su enseñanza en un contexto pluralista y humanizante. (Tesis de maestría en educación). Universidad de Antioquia, Medellín, Colombia.

Meléndez, A. (2015). Pluralismo Religioso en el Mundo Contemporáneo. Universidad Autónoma de Madrid, España. Doi: 10.13140/RG.2.1.1807.2081.

Meza, J.L et al. (2011). Educación religiosa escolar. Naturaleza, fundamentos y perspectivas. Bogotá: San Pablo.

Ministerio de Educación Nacional. (2004). Directiva Ministerial 002. Recuperado de http: //www.mineducacion.gov.co/1759/ articles-86181_archivo_pdf.pdf

Ministerio de Justicia. (2006). Decreto 4500, recuperado de http://www.suin-juriscol.gov.co/viewDocument. asp?ruta $=$ Decretos $/ 1546945$

Magendzo, A. (2007). Reflexión en torno a la educación religiosa en una perspectiva de educación religiosa pluralista. Revista internacional Magisterio, Educación y pedagogía. (30). 15-17.

Moncada, C. (2020). La inteligencia espiritual en el aula de clase. Ruta Maestra, (28), 1-3. Recuperado de https://rutamaestra. santillana.com.co/edicion-28/la-inteligencia-espiritual-en-el-aula-de-clase/
Moncada, C. y Barreto, F. (2018). Philosophy of religion and Religious Education in School. En: Botero, C. y Hernández, A. (Editores). Approaches to the Nature and Epistemological Foundations: Of Religious Education in Colombian Schools (107-128). Bogotá, D.C. Ediciones USTA. DOI: $10.2307 /$ j.ctvr33dht

Morin, E. (1999). Los siete saberes necesarios para la educación del futuro. UNESCO; Pontificia Universidad Javeriana: Bogotá.

Naranjo, S. y Moncada, C. (2019). Aportes de la Educación Religiosa escolar al cultivo de la espiritualidad humana. Revista Educación y Educadores 22(1), 103-119. Recuperado de https://doi.org/10.5294/edu.2019.22.1.6

Pérez, J. (2017). La Teología en relación a la ERE, un llamado a la educación en la pluralidad. Revista Cultura, (274), 21-24. Recuperado de https://conaced.edu.co/wp-content/uploads/2017/08/Revista-274-final..pdf

Perilla, A., Ramírez, S y Agudelo, A. (2019). Impacto de las Tecnologías de la Información y la Comunicación (TIC) en la formación ética y religiosa de estudiantes de educación media vocacional*. Revista Electrónica de Educación Religiosa, Didáctica y formación de profesores, 9, (1). 1-31.

Restrepo, L. G. (2015). "Revelación y teología de las religiones: J. Dupuis y A. Torres Queiruga en diálogo." Theologica Xaveriana, 65, (180), 447-470. Recuperado de http:// dx.doi.org/10.11144/javeriana.tx65-180.rtr 